\title{
THE LINK BETWEEN INTERPERSONAL VIOLENCE AND ANIMAL ABUSE
}

\author{
AVIVA VINCENT ${ }^{1}$, SHELBY MCDONALD ${ }^{2}$, BETHANIE POE $^{3} \&$ VICKI DEISNER $^{4}$ \\ ${ }^{1}$ Corresponding author: Case Western Reserve University, Mandel School of Applied Social Sciences, \\ 11235 Bellflower Road, Cleveland, Ohio 44106, USA. ORCID: 0000-0003-2527-940X, Email: aviva.vi- \\ nent@case.edu \\ ${ }^{2}$ Virginia Commonwealth University, Richmond, Virginia 23284, USA. ORCID: 0000-0001-6094-6234, \\ E-mail: smcdonald@vcu.edu \\ ${ }^{3}$ University of Tennessee, Knoxville, TN 37996, USA. ORCID: 0000-0002-5344-847X, Email: bpoe2@ \\ utk.edu \\ ${ }^{4}$ Government Affairs Representative in Ohio for the Animal Welfare Institute, USA. ORCID: N/A, Email: \\ vicki.deisner@gmail.com
}

ABSTRACT: In 2018, more homes in the US have pets than those that have children. Though pets are regarded as property by US law, a majority of people identify pets as part of the family unit. Animal abuse and cruelty have been identified as a potential indicator and precursor to interpersonal violence (IPV). Moreover, child maltreatment, domestic violence, elder abuse, and animal abuse co-occur in households and communities link together to indicate the nexus of these heinous crimes; these co-occurring forms of violence have been increasingly referred to as The Link, to indicate the linked violence. However, there is an incongruence in the definition of animal abuse and cruelty; thus, documenting cases, bringing charges, and achieving a conviction is difficult. Furthermore, the initial education to learn of these topics in human service professions, such as social work, remains absent from many curricula. In practice, cross-reporting of suspected abuse or neglect is a vital mechanism for connecting human and animal professionals to address the issues between human and animal welfare systems. This sharing of information can increase the likelihood that clients experiencing IPV will receive comprehensive services that can improve their 
level of safety and quality of life. By providing professionals with education for indicators of abuse, and strategies for how to make a report, communities can build stronger support networks for those in need. Herein, Ohio legislation and current community efforts serve as a case study to define animal abuse, delineate transdisciplinary factors for relevance, and make recommendations for addressing this vital social welfare need. The strategies within this case-study are encouraged to be adapted and applied nationally and internationally.

KEYWORDS: interpersonal violence, cross-reporting, animal abuse, social work, The Link

\section{INTRODUCTION}

The Link is a term used to refer to the concordance of interpersonal violence (IPV) and animal abuse and neglect. Just as IPV occurs between two or more people within the context of a relationship, animal abuse and neglect are a tactic that occurs in the context of IPV. Rather than considering violence against pets as separate to IPV, considering animals as part of the family structure, impacted by violence in the same manner as their human counterparts, sheds light on instances of animal abuse and neglect as part of the familial cycle of violence. Pets occupy a central role in many relationships and families (Turner 2006), and can serve as a source of companionship, a confidant (McNicholas \& Collis 2006), and a vital member of an individual's support system (Wood et al. 2015). Being part of the family means that the relationships between humans and animals in a household may mirror the status of the health and safety of the people in that family (Hoffer, Hargreaves-Cormany, Muirhead \& Meloy 2018).

Given the authors' scope of practice, predominantly as social workers, content relevant to mental health, is discussed through a social welfare lens of practice and education. Though medical and mental health professions have mandatory education and reporting for child abuse, elder and animal abuse are still absent from many educational curricula and standards of practice. Social work remains a human-centered field of study and practice. Many social work professionals do not have sufficient education regarding The Link as it is not yet commonplace in educational curricula. Inclusion of pets throughout social work, clinical and community practice, is vital to understanding the health and well-being of clients holistically. As such, if a practitioner is not taught how to define, identify, and report animal abuse in the classroom, it is not reasonable to assume they will engage in such practices once coursework concludes (Risley-Curtiss 2010).

Social Workers may feel unqualified to judge what is report worthy, nor may they know to whom a report should be made. Without education and organizational support, reporting animal abuse may be a conceptually low priority in social service agencies where resources such as time and money are lacking. Concern as to whether making this report will damage the social work professional's relationship with the client, as well as the potential lack of professional protection, can make reporting animal 
abuse an anxiety-provoking proposition. Other objections for reporting include fears of violating client confidentiality, lack of training to identify and report suspected abuse, and the lack of a unified definition of abuse. Without clear standards for reporting, social workers may be reluctant to involve another government agency, such as police or animal control, for fear of making a client situation even more complicated (Favar \& Strand 2008). Given the new evidence of The Link, it is imperative that mandated reporting of abuse and neglect is inclusive of animals across multiple health professions including social work, medical/health, veterinary, and allied professions (Simmons \& Lehmann 2007; Febres et al. 2014; Roguski 2012).

\section{ABUSE DEFINED}

In Link-related research, animal abuse has historically been defined similarly with slight, but critical, variations of the language. One common definition is '[s]ocially unacceptable behavior that intentionally causes unnecessary pain and suffering, or distress to and or death of an animal' (Ascione 1993: 28). Similarly, Agnew defined abuse as '[a]ny act that contributes to the pain or death of an animal or that otherwise threatens the welfare of an animal' (1998: 179). In this definition, even socially acceptable behaviors, like hunting, may be considered abuse. Thus, it is essential to use a definition that is socially and culturally acceptable as a baseline, then modify as appropriate to meet the needs of the community. The definitions of animal abuse or cruelty are typically more pragmatic in the day-to-day application by law enforcement or animal control. State laws as well as local ordinances specify the parameters of what is or is not legally a form of animal abuse; descriptions of abuse generally include intentional physical injury or death of an animal, and the lack of appropriate food, water, shelter, or medical care, along with definitions of what is considered 'appropriate' standards for animal care.

Animal abuse can take many forms that often parallel human abuse: neglect, physical abuse, animal sex abuse (also referred to as zoophilia, or interspecies sexual assault), and animal fighting (Randour 2008). As in the case of children and the elderly, neglect is the most common form of harm towards animals and may include the lack of appropriate food, water, shelter, or medical care. Most active forms of physical abuse are inflicted to control, retaliate, satisfy a prejudice, or meet a desire for non-specific sadism. Abuse of animals by children is one of the strongest predictors of later abuse (DeGue \& DiLillo 2009). With this understanding, researchers and practitioners are better able to understand and support those who are marginalized and at-risk.

\section{STATE OF RESEARCH ON ANIMAL ABUSE AND INTERPERSONAL VIOLENCE}

Increasingly throughout the past two decades, leaders in violence and trauma prevention have advocated for the importance of assessing for co-occurring violence exposures in research and practice (e.g., Finkelhor, Turner, Hamby, \& Omrod 2011; Musicaro et al. 2017). Despite the fact that growing evidence of the frequent overlap of animal abuse with intimate partner violence, child maltreatment, and elder abuse, the Link 
between interpersonal violence and animal abuse remains vastly under-researched and discussed in academic and practice settings. Moreover, a majority of studies to date have been cross-sectional and/or retrospective in design. Within this body of work, studies have primarily focused on two major areas of The Link violence: 1) associations between animal abuse and intimate partner violence, and/or 2) associations between childhood animal cruelty and adult violence. In this section, we discuss the current state of research in these areas, review gaps in the literature, and recommend future directions for social work research.

\section{ANIMAL ABUSE AND DOMESTIC VIOLENCE}

Much of the work examining links between animal abuse and family violence has centred on understanding the prevalence and function of animal abuse in the context of intimate partner violence. Ascione and colleagues conducted much of the early research in this area. In a national survey of the largest U.S. shelters serving women and child survivors of domestic violence (DV), Ascione, Weber, and Wood (1997) found that $83 \%$ of surveyed shelters indicated that they had observed the coexistence of DV and animal abuse in their work. In a later study of women accessing DV services, Ascione (1998) found that $71 \%$ of pet-owning women reported their partner had threatened and/or killed their pet. Indeed, Ascione (2007) found that women accessing IPV services were nearly 11 times more likely than a comparison group of non-victimized women in the community to report that their partners had hurt or killed a pet on purpose. Animal abuse by DV perpetrators may take on many forms (hitting, burning, intimidating, choking, shooting; McDonald et al. 2015) and may be a mechanism of coercion to influence an intimate partner, a reactive disciplinary response to animal behavior, a coercive parenting tactic, and/or rooted in other motivations (Collins et al. 2018; DeGue 2011; Hardesty, Khaw, Ridgway, Weber \& Miles 2013). DV perpetrators may be more likely to engage in animal abuse if their victim has a strong bond with the pet (Collins et al. 2018).

Due to the strong bonds many DV survivors have with their pets, animal abuse may exacerbate the psychological trauma of DV abuse and serve as an additional obstacle in many survivors' safety planning efforts. Ascione et al. (2007) reported that nearly $22 \%$ of DV survivors delay entering a shelter because of concerns for their pet. This may be further exacerbated by children's attachments to pets, although few studies have examined how children's relationships with abused and non-abused pets impact safety planning and survivors' ability to access shelter services (Collins et al. 2018). A 2012 study conducted by Krienert and colleagues found that only 6\% of DV services offered pet-sheltering or fostering services. Given increased attention to this issue in the past few years, as well as increased legislative progress that has resulted in many states permitting pets to be included on protection orders in domestic violence situations, we suspect this number has increased in recent years. However, we are unaware of any nationally representative research reporting on the prevalence of pet-sheltering and pet-fostering services in the United States since 2012. 


\section{INTERSECTION OF ANIMAL AND CHILD WELFARE}

Generally, knowledge concerning how animal abuse impacts children in households experiencing IPV is limited. Several recent studies indicate that exposure to animal abuse is a robust predictor of compromised adjustment in children. For example, McDonald et al. (2016) found that animal cruelty exposure was associated with increased risk of compromised socioemotional functioning among 291 children recruited from community-based DV services. Specifically, children exposed to animal abuse were 3.26 times more likely than children with no animal abuse exposure to experience co-occurring internalizing and externalizing problems, and 5.72 times more likely to experience co-occurring behavior problems, attention problems, social problems, and callous/unemotional traits that were clinically significant. Moreover, McDonald et al. $(2016,2017)$ found that exposure to animal abuse was the strongest predictor of children's compromised adjustment in a model that included the severity of exposure to maternal IPV and other sociodemographic factors (e.g., gender, household income).

Similar findings have been mirrored and expanded upon in retrospective reports with adult samples. For example, Girardi and Pozullo (2015) found a significant interaction between participants' level of bonds with pets and animal abuse exposure, controlling for co-occurring emotional abuse in childhood. Adults who reported medium-level bonds with pets who were exposed to animal abuse in childhood had significantly higher depression and anxiety scores in adulthood than those who were not exposed to animal abuse. In contrast, adults who reported medium-level bonds with pets and had not been exposed to animal abuse in childhood had lower anxiety and depression scores in adulthood than those with low-level bonds.

As previously mentioned, animal abuse may take many forms in households affected by DV, and there is emerging evidence that it may be important to consider the type of animal abuse to which children are exposed. McDonald et al. $(2015,2018,2019)$ suggest that children living in households where IPV occurs are exposed to multiple manifestations of violence involving animals, including 1) animal abuse as a coercive DV tactic, 2) animal abuse as a coercive parenting tactic, 3) animal neglect, 4) cruel play by siblings, and 5) harsh physical punishment/discipline of pets. Moreover, children may be more likely to intervene in specific forms of animal abuse. For example, McDonald et al. (2015) report that children may be more likely to become involved in incidents of DV involving animals, which may increase their risk for physical injury or death by a caregiver. To date, children's involvement in violent animal-related incidents has largely been ignored in research and intervention with families affected by DV, yet this work has important implications for understanding risks to children's health and wellbeing, as well as their intervention needs. In particular, children exposed to DV are at greater risk for perpetrating animal cruelty, which has been linked with antisocial behavior across the lifespan (Baldry 2005). A cross-sectional study by Currie (2006) found that among a community-sample of U.S. children ages 5 to 17 years, those who reported exposure to DV (17\% of the sample) were nearly three times more likely to report having engaged in animal cruelty than children who had not been exposed to DV. 
Although evidence of links between exposure to animal abuse and compromised adjustment in childhood and adulthood is increasing, it is important to note that a major limitation of prior research has been investigators' reliance on cross-sectional data and the inability to adjust for the potential confounding effects of co-occurring child maltreatment and/or other forms of violence that overlap with IPV (e.g., community violence). Deviney, Dickert, and Lockwood (1983) found that animal abuse was present in $88 \%$ of households with substantiated reports of child maltreatment. In addition, a recent study of Child Protection Workers in Canada found that $44 \%$ had observed an animal be physically abused during an investigation in the past year. Ninety-four percent reported that they had observed evidence of animal neglect in the past year during an investigation.

\section{CHILDHOOD ANIMAL CRUELTY AND ADULT INTERPERSONAL VIOLENCE}

The Link between animal abuse in childhood and later violence toward humans and animals has also received increased attention in the past few decades. As previously mentioned, abusing animals during childhood is linked to later violence and antisocial behavior, including abuse of children, spouses, and elders (Walton-Moss, Manganello, Frye \& Campbell 2005). Bullying and delinquent behaviors have also been extensively documented in childhood animal abusers (Becker, Stuewig, Herrera \& McCloskey 2004; Gullone \& Robertson 2008). Moreover, childhood animal abuse is receiving increased attention as an indicator of early childhood trauma and adversity (Bright, Huq, Spencer, \& Applebaum 2018). Several cross-sectional and longitudinal studies link childhood animal abuse to family violence exposure, including violence against pets (McDonald et al. 2018b). A recent retrospective study of juvenile offenders across nine years found that youth who engaged in animal abuse were more likely to have experienced more than four adverse childhood experiences ('ACEs'), and present to law enforcement at early ages. Thus, attention to childhood animal cruelty is essential for early intervention and trauma-informed violence prevention.

Relatedly, another aspect of The Link that has received increased attention is the association between animal abuse and adult crime. A recent study of men incarcerated for domestic violence-related offenses found that 38\% reported abusing animals in childhood and nearly $86 \%$ reported abusing animals at some point in their lifetime (Haden, McDonald, Booth, Ascione \& Blakelock 2018). This study also found that childhood animal abuse was significantly associated with psychological abuse and sexual coercion in the context of intimate relationships. It should be noted that there is a relatively weak association between animal abuse and violent crime, as the majority of people who perpetrate animal abuse do not go on to engage in violence offenses against people (Patterson-Kane 2016). Instead, animal abuse should be viewed as one of many risk factors for later violence, criminal behavior, and the intergenerational transmission of family violence behaviors. 


\section{LIMITATIONS AND DIRECTIONS FOR RESEARCH}

Although this emerging body of work points to the important links between IPV, animal abuse, and child welfare, nationally representative longitudinal studies of ethnically and culturally diverse samples are needed. This is particularly important given the rapidly changing U.S. demographics and changing social context. For example, there is some evidence that the use of animal abuse as a coercive control tactic is less prevalent among Latino populations, particularly immigrants from Mexico (Hartman, Hageman, Williams \& Ascione 2018). African American and Black families have been sorely underrepresented in research in this area, along with other ethnic and cultural minority groups. Similarly, research omits other marginalized and underrepresented groups such as elders and the connection with elder abuse (Peak, Ascione and Doney 2012; Arkow 2015). It is important to determine the cross-cultural relevance of The Link when informing related practice and policy changes, and to identify how the intersection of multiple minority identities (e.g., race, religion, sexual orientation, disability) may impact relations between violence to human and non-human animals within households and communities.

\section{STATE OF PRACTICE: CROSS-REPORTING}

Cross-reporting is centred upon the idea that no one profession is equipped to address any and all situations that may arise within a client system, and therefore it is necessary to seek assistance from and share information with professionals in other specialties. Cross-reporting is an intentional strategy that can improve the community's response to crimes against both people and animals and may also help prevent future violence. The notion of cross-reporting presupposes that four types of family violence - DV, child abuse, elder abuse, and animal abuse - rarely occur in a vacuum (Ascione 2005; Ascione 2008; Ascione \& Arkow 1999). They often overlap, and the commission of one of these crimes often is a 'red flag' that other forms have occurred or will be coming next. For various reasons, animal cruelty, abuse, and neglect are often the sentinel warning signs, and the first 'link' in the chain of family violence (Ascione 2005).

While the primary discussion is on the role of social workers and animal control in cross-reporting, there are several other key professions who much be engaged to be successful. At a minimum, veterinarians, legal professionals, and medical doctors should also be active contributors and collaborators. Fields allied to social work, such as child protective services and departments for ageing are also assets to effective community service. Specifically, the inclusion of veterinarians among required reporters of animal abuse may aid in saving animals' lives as well as their human counterpart.

Laws for reporting abuse vary by state, most notably in two aspects. First, by which professionals are mandated to report abuse. For example, in some states, only particular professions are mandated reports of child abuse, while in others every resident of the state is considered a mandated reporter. Secondly, states vary by whether professionals are required or permitted to report suspected abuse. Additionally, while some level of mandated reporting of child and elder abuse is present in all fifty states, laws 
requiring the reporting of animal abuse are nowhere near so prevalent. This legal variation from state to state can leave mental health professionals with an ethical dilemma. For example, the National Association of Social Workers (NASW) Code of Ethics is intended to guide social workers to enhance human well-being. As such, questions about client privacy and confidentiality often come to the forefront when the issue of reporting animal abuse is discussed. In some states, cross-reporting laws specify the type of professional that can report animal abuse in the course of their work. For example, in the state of Tennessee, the cross-reporting law (Tennessee Code Annotated 38-1-402) specifically names government officials working in child protective or adult protective services as mandated to report animal abuse they encounter or suspect in the line of duty (National Link Coalition 2019). However, what about a social worker that learns about animal abuse during a therapy session? Or on a home visit from a non-government agency? What obligation or protection those social workers may have is unclear.

Cross-reporting is a mechanism for agencies to have a current and connected picture of the violent acts that are occurring in a specific environment (i.e. household) which may enable the agencies to develop more effective intervention strategies. If a social worker, in the course of a home visit necessitated by reports of child maltreatment, elder abuse, or DV, sees signs of animal abuse and is required to contact animal control/humane enforcement, they may have the ability to save an animal's life and help to prevent the escalation of violence in the household.

As an example, an animal control officer made a report regarding a parent with young children wherein the parent attests to beating the family dog with a belt. Using this report as a guide, the child protective services worker was alerted to look for specific types of physical injuries on the children (i.e., belt marks). Another example, applying a recent case from Franklin County, Kentucky, deputies arrested a woman on elder abuse charges with a warrant issued for animal cruelty and neglect of an adult. This situation came to light because, while deputies were doing a welfare check on the animals at home, they found her 75-year-old mother on the floor covered in animal feces. Four of the nine dogs in the house had to be euthanized due to their health status (Blair 2017). With appropriate training, as well as state and organizational policies and procedures, cross-reporting can be a useful tool for both animal and human welfare professionals.

\section{USING DATA TO INFORM POLICY}

Compounded data over the last four decades have illuminated the need to address The Link in the policy. Key data points that have been raised as justification for political engagement include: a review of New Jersey families $(n=53)$ that were referred to the state for physical assault of children, and found that pet abuse was present in $60 \%$ of those homes (DiViney, Dickert \& Lockwood 1983); in a retrospective, cross-sectional study of college students ( $n=860), 60 \%$ of participants who witnessed or engaged in animal cruelty also experienced either child maltreatment or DV (DeGue \& DiLillo 2009). In another study, $41 \%$ of men arrested for DV had committed at least one act 
of animal cruelty since age 18 (Febres 2014). Perhaps most significantly, pet abuse is one of the four primary risk factors associated with men who become batterers (Walton-Moss, Manganello, Frye \& Campbell 2005). Locally, a 2010 survey of state DV programs by the Ohio Domestic Violence Network (ODVN) reported that more than $40 \%$ of respondents recalled cases where pets had been threatened with harm, actually harmed or killed (ODVN 2019). Culling together data has led to momentous efforts to advance state and national policy to support the needs of victims and survivors of The Link.

The Link was acknowledged in September 2014 when the Federal Bureau of Investigations (FBI) Director approved the recommendation from the Criminal Justice Information Services Advisory Board to add animal cruelty crime data to the Uniform Crime Report - National Incident-Based Reporting System (UCR-NIBRS) (National Link Coalition LINK-letter, October 2014). Most recently, the recognition of The Link was explicitly considered when Congress passed the Pet and Women Safety (PAWS) Act in the 2018 Farm Bill, which extends current federal DV protections to include pets and authorizes \$3-million dollars per year in grant money through 2023 for emergency and transitional housing options for DV survivors with companion animals.

The growing body of research illustrating the correlations between the presence of IPV and violence towards animals, as well as an increase of public awareness of The Link, has prompted many states to enact laws, or combinations of laws, to increase cross-reporting. In general, these laws stipulate that while working in an official capacity, protective service professionals and animal welfare professionals who observe abuse or neglect of children, vulnerable adults, or animals, respectively, are obligated to report their observations to the appropriate agencies. An example of a combination of laws that enables cross-reporting would be if a state already had mandatory reporting of child abuse or elder abuse, and a new law is passed that allows social workers to report suspected cases of animal abuse (i.e. House Bill 33 in Ohio 2019). In addition to mandating what must be reported, the laws typically specify to whom agency's reports must be made, and the timeframe within which a report should be filed.

In response to the need to cross-report family violence between professions, professionals in multiple disciplines are actively re-examining the complex motivations behind acts of animal cruelty, advancing innovative public policy reforms, implementing programmatic innovations, and using animal-assisted interventions to help the perpetrators and victims of violence. One such mechanism is state-level legislation to facilitate cross-reporting among human services and animal protection agencies that would provide civil immunity for reporting. This policy would also provide civil immunity for reporting in good faith and workshops that provide professionals with ongoing education to refine their skills towards effective cross-reporting.

\section{MANDATORY VS. VOLUNTARY CROSS-REPORTING}

The current approach states have taken is split between mandatory vs. voluntary reporting (full state-by-state list accessible at National Link Coalition 2019). Though many advocate for cross-reporting to become mandatory, the systems must be estab- 
lished with protocols and processes to do so. Currently, states that have passed laws regarding the reporting of animal abuse are split between mandatory and voluntary reporting.

In regard to reporting child abuse, nine states mandate humane agents/animal control officers to place reports formally, three states mandate veterinarians to report, and seventeen states mandate all professions to report suspected abuse. Regarding veterinarians reporting animal abuse: 16 states mandate reporting, nineteen states permit voluntary reporting, and one state, Kentucky, prohibits reporting. Regarding Adult Protective Services reporting animal abuse: four states mandate reporting, and one state, California, permits voluntary reporting. Animal abuse reporting by Child Protective Services and social workers is mandated in seven states and permitted voluntarily in five (National Link Coalition 2018).

For professions initially coming under mandatory reporting, questions often arise as to how to benchmark a specific type of abuse, and who the primary community contact is for the entities to which abuse reports are to be made. These questions cannot be answered by the legislature, making it important to have organizations step in to provide training and networking of diverse professions on a local level. In order for cross-reporting to be efficiently implemented, both animal and human welfare professionals need to be trained regarding their respective issues. Through education opportunities, agencies can build cooperative relationships in which each agency has a clear understanding of what the other does, its general policies, and what its limitations are. To ensure that the trainings are accessed, licensing and credentialing bodies are encouraged to make continuing education mandatory, just as the medical community did for child abuse in the 1990s.

In addition to identifying the appropriate oversight entity if mandatory reporting is required, state legislatures must also determine the appropriate profession to receive abuse reports. When abuse is suspected or confirmed, knowledge of the process to make a report is essential. This is often a barrier either because of lack of access, professional fear of reporting, or lack of knowledge for whom to report to. Furthermore, professionals must be aware of their licensing body's stance and state policy on mandatory reporting. Information regarding protection for those who place a report is beneficial to increasing the potential of report claims. Lastly, professionals may benefit from education about what content is necessary for a report. Providing accurate information increases the likelihood of professionals engaged in cross-reporting receiving the information they need to follow through with an investigation. Mostly, the questions that social workers and allied professions need to address to be effective in their role are: Who is responsible for making the report? What is the time frame in which a report should be made? How is the report to be made (telephone, website, in writing, etc.)? Will clients be informed that a report was made?

Similar to any direct service field, client privacy and confidentiality are always of concern in social work practice. One way some organizations address this issue is by adding language regarding the reporting of animal abuse to their informed consent policies; similar to the statement for reporting self-harm or harm to other persons. This way, the client is aware of the parameters of confidentiality before beginning 
with the social worker, should animal abuse conversations arise.

\section{TOWARDS ESTABLISHING CROSS-REPORTING: THE OHIO MODEL}

As of 2018, Ohio hosts a population of 11.69 million, of which 2.6 million are children. Within these homes, there are 2.73 million dogs and 3.79 million cats. As cited by Arkow (2019), Ohio law enforcement averages over 177 calls per day, with approximately 25 calls per hour to the crisis hotline. On average, there are 47 civil protection orders filed, and 456 reports per day for child abuse. Of the abuse reports made, $48 \%$ are for neglect, $43 \%$ for abuse, and 19\% for sexual abuse and $48 \%$ of these reports meet the threshold to be evaluated (Arkow 2019).

Ohio's current animal abuse language falls under the Animal Security Ordinance (959.01-959.99) which specifically mentions: abandonment, malicious or willful injury of an animal, poisoning, and dog/cock fighting. The state was an early pioneer in developing a cross-reporting mechanism. States' humane societies have been empowered to investigate child abuse as well as animal cruelty for decades (i.e. ORC 1717.14). Similarly, to those in law enforcement, cross-reporting has been in place in Ohio for a long time (i.e. ORC 1717.01-1717.15, 174). This is because humane officers, animal control, and police have worked in concert with relative efficiency. However, other human and animal serving professionals have been omitted from the table, including social workers, veterinarians, and other allied professionals.

The national trend is to work toward mechanisms to support cross-reporting of animal, child, and elder abuse which is an initiative the Animal Welfare Institute (AWI) is actively engaged in (AWI 2018). A cross-reporting mechanism aims to ensure that inter-professional communication occurs in an effective and timely manner. When suspected abuse occurs, a communication chain is triggered to ensure that the human and animal needs are promptly addressed. Ohio is actively engaged in developing this mechanism from grassroots and policy levels simultaneously.

\section{LEGISLATION}

Ohio policymakers have recognized The Link over the last several years through the passing of legislation. AWI has successfully advocated for animal welfare legislation in the state related to family violence issues including pet protective orders, animal sexual abuse, and felonies for extreme animal cruelty (i.e. ORC 3113.31 (F) (3), 959.21, 959.31, 959.99, and protective order form 10.01-M). While serving as legal tools to address animal abuse, each legislative success is useless if the abuse is not being reported. In Ohio's 2019-2020 general session, AWI worked with the Ohio legislature to introduce House Bill 33, which requires cross-reporting between human services and animal protection agencies. Ohio's House Bill 33 mandates veterinarians, licensed social workers, social service professionals, law enforcement, humane agents and dog wardens to file reports. With the push of House Bill 33, the landscape and conversation have shifted to be far more inclusive and specific.

A thorough effort was made to research the issues of reporting, and work with all 
named professions to assure the legislation would bring about positive change in addressing IPV. This included working with each profession's state representative to determine what entity would be the appropriate oversight body for the professionals and whether there would be warnings and penalties for those who do not report. Through conversation, representatives decided that the lack of reporting will likely trigger a violation that may take the form of a warning, a penalty, or a misdemeanor. NASW-Ohio has been active in this conversation as social workers would become mandated reporters of animal abuse should this bill pass. As such, representation from NASW has been taking on the challenge of identifying an appropriate entity to provide oversight of professionals and facilitating conversation towards agreement on fair a repercussion should the reporting not be completed as determined by the law. These are difficult challenges for state legislatures - identifying appropriate professional representation has been an asset for the social work community.

However, the passage of legislation does not guarantee the successful implementation of the laws, nor does it educate the professionals responsible for implementation. Inter-professional relationships are essential to ensuring that effective cross-reporting occurs. To achieve this aim, seminars were designed and conducted in an effort to strategically curate relationships between human and humane services that lay the foundation necessary for successful cross-reporting.

\section{COMMUNITY OUTREACH}

Through the seminars, titled Cross-Reporting for Humane and Human Services: A Species-Spanning Approach to Safer Families and Communities, supported by the Kenneth A. Scott Foundation Trust, a KeyBank Trust, and Maddie's Fund ${ }^{\circledR}$, AWI conducted regional training in three of Ohio's major cities - Toledo, Cleveland, and Columbus. AWI will conduct similar workshops in Dayton, Cincinnati and Athens this coming year. The conversation focused on The Link and its implications for human and humane services. The seminars described new strategies, public policy, research, and programs to prevent family violence and how to respond to its human and animal victims.

The target audience for the seminars included professionals working with human or animal abuse including social workers, humane agents, dog wardens, veterinarians, law enforcement and prosecutors - many of the same professions included in the Ohio legislation, House Bill 33. It was thus critical for AWI to collaborate with national, state and local partners to assist in strategy, logistics, and the marketing of the seminars. AWI recruited the National Link Coalition, Ohio Domestic Violence Network (ODVN), the Ohio Animal Welfare Federation, the Ohio Veterinary Medical Association, Ohio State Bar Association, NASW, Case Western Reserve University Mandel School of Applied Social Sciences, University of Toledo College of Social Justice and Human Services, Cleveland Animal Protective League, Toledo and Columbus humane societies, and Central Ohio Area Agency on Aging. NASW, Ohio State Bar Association, and Ohio Veterinary Medical Association, through the Ohio Veterinary Medical Board, provided continuing education units for professionals in attendance.

The seminars were arranged to allow interaction among professions throughout 
the day, including group discussion to generate ideas on how to enhance professional relationships and develop communication processes that foster cross-reporting. In the group discussions, many social workers shared that they were not aware of The Link between animal and human violence and were thankful for the information and opportunity to incorporate this knowledge into their practice. Social workers also identified the need to either expand or create local multidisciplinary task forces, that include humane agents, so that all aspects of family violence could be addressed.

The result of this work nationally is an increase in conversation about the importance of recognizing The Link, and concrete objectives to effectively address the human and animal needs that arise. At the macro level, the FBI generated database has aided researchers in understanding the longitudinal effects of The Link and human behavior. Mezzo practice has included robust community efforts towards establishing co-shelter organizations, developing state-wide legislation, and interdisciplinary cross-reporting mechanisms. The micro practice is ever evolving as the conversation becomes more robust. Practitioners have increased access to webinars, course content, and peer-reviewed literature to aid in developing a common language, questions to ask, and cues for noticing The Link.

\section{CONCLUSION}

Pets are vital and vivacious members of the family unit throughout millions of American homes. The Link recognizes the multifaceted relationship between child maltreatment, domestic violence, elder abuse, and animal abuse that may co-occur in household or community. Interdisciplinary education, with a unified definition of animal abuse and neglect and clear professional standards of practice, may help professionals to identify suspected maltreatment, and initiate effective support inclusive of reporting. In particular, social work education is encouraged to move away from its human-centered roots and embrace our multispecies homes.

In practice, cross-reporting of suspected abuse or neglect is a vital mechanism for professionals to connect human and animal welfare systems. This sharing of information can increase the likelihood that individuals experiencing IPV will receive comprehensive services that can improve their level of safety and quality of life. Though Ohio is actively pursuing legislation to enact professional mandates and a state-wide cross-reporting system formally, there is still much work to be done. Other states are engaged in this work as well and are at varying stages of success. Some states have active community practices (i.e. hotline phone numbers that can be called to trigger the cross-reporting system) but limited policy, while other states have a robust state-wide policy, but no mechanism. By working from the grassroots and policy level simultaneously, Ohio is effectively establishing policy and practice that reinforce each other.

The Ohio model utilizes legislation, professional training and local multi-disciplinary task forces to implement cross-reporting of human and animal violence among diverse professions responsible for investigating family violence. No singular profession can address The Link independently; efforts must be interdisciplinary. Educational training must be offered regularly and in a uniform manner so that all inter- 
disciplinary professionals can work in concert with the same language, understanding, and aims. To that end, the opportunities for accessible (i.e. continuing education credit, low/no cost) webinars have been increasing in frequency and attendance. This is similar to the education regarding child abuse in the 1990s, which was mandated by medical professionals.

When, not if, social workers become mandated reporters of animal abuse, so too should The Link content be mandatory in continuing education and social work curricula. The overall aim is to increase the likelihood that individuals experiencing family violence will receive comprehensive services that can improve their level of safety and quality of life, and that animals experiencing violence receive prompt aid. By providing professionals with guidance with what to look for and how to make a report, communities can build stronger support networks for those in need. In this regard, cross-reporting has the potential to be a useful tool in the assessment for The Link.

FUNDING: This research received no external funding.

CONFLICT OF INTEREST: The authors declare no conflict of interest.

ACKNOWLEDGEMENTS: We would like to acknowledge the on-going research at multiple Universities and the community efforts of The National Link Coalition, the Kenneth Scott Charitable Trust, and Maddie's fund for their support and efforts to address The Link.

\section{REFERENCES}

Agnew, Robert. 1998. "The causes of animal abuse: A social-psychological analysis.” Theoretical Criminology 2(2): 177-209.

American Pet Products Survey (APPA). 2018. National Pet Owners Survey. Retrieved September 5, 2019 (https://www.americanpetproducts.org/pubs_survey.asp).

Animal Welfare Institute. 2019. State Comparisons of Cross-Reporting Laws. Retrieved September 5, 2019 (https://awionline.org/awi-quarterly/summer-2019/cross-reporting-workshops-address-animal-abuse-and-family-violence).

Arkow, Phil. 2015. A link across the lifespan: animal abuse as a marker for traumatic experiences in child abuse, domestic violence and elder abuse. Shakopee, MN: Academy on Violence and Abuse.

Arkow, Phil. 2019. Cross-Reporting for Humane and Human Services: A Species-Spanning Approach to Safer Families and Communities. Community Presentation: Cleveland, Toledo and Columbus, Ohio.

Ascione, Frank R. 1993. "Children who are cruel to animals: A review of research and implications for developmental psychopathology.” Anthrozoös 6(4): 226-247.

Ascione, Frank R. 1998. "Battered Women's Reports of Their Partners' and Their Children's Cruelty to Animals.” Journal of Emotional Abuse 1(1): 119-133.

Ascione, Frank R. 2005. "Children, animal abuse and family violence - The multiple intersections of animal abuse, child victimization, and domestic violence.” Pp. 3-35 in Child Victimization, Maltreatment, Bullying and Dating Violence: Prevention and Intervention, edited by K. A. Kendall-Tackett and S. M. Giacomoni. Kings- 
ton, NJ: Civic Research Institute.

Ascione, Frank R. 2005. "Children, animal abuse and family violence - The multiple intersections of animal abuse, child victimization, and domestic violence." Pp. 3-1 - 3-36 in Child Victimization: Maltreatment, Bullying and Dating Violence: Prevention and Intervention, edited by K.A. Kendall-Tackett \& S.M. Giacomoni. Kingston, NJ: Civic Research Institute.

Ascione, Frank R. 2008. International Handbook of Animal Abuse and Cruelty: Theory, Research, and Application. West Lafayette, IN: Purdue University Press.

Ascione, Frank R. and Phil Arkow. 1999. Child Abuse, Domestic Violence and Animal Abuse: Linking the Circles of Compassion for Prevention and Intervention. West Lafayette, IN: Purdue University Press.

Ascione, Frank R., Shelby McDonald, Phil Tedeschi and James Herbert Williams. 2018. “The relations among animal abuse, psychological disorders, and crime: Implications for forensic assessment." Behavioral sciences \& The Law 36(6): 717-729.

Ascione, Frank R., Claudia V. Weber, Teresa M. Thompson, John Heath, Mika Maruyama, and Kentaro Hayashi. 2007. "Battered pets and domestic violence: Animal abuse reported by women experiencing intimate violence and by nonabused women." Violence against women 13(4):354-373.

Ascione, Frank R., Claudia V. Weber and David S. Weber. 1997. “The abuse of animals and domestic violence: A national survey of shelters for women who are battered." Society \& Animals 5:205-218.

Associated Press. 2019. "New Mexico man accused of animal abuse; vet says cat on meth.” Associated Press, August 13, Retrieved December 18, 2019 (https://apnews.com/41de536bb5fb4ad882251dd8132e162e).

American Veterinary Medical Association (AVMA). 2018. Cross-reporting of child and animal abuse. Retrieved December 18, 2019 (https://www.avma.org/Advocacy/ StateAndLocal/Pages/sr-animal-abuse-cross-reporting.aspx).

American Veterinary Medical Association (AVMA). 2018. "Abuse Reporting Requirements by State.” Retrieved December 18, 2019 (https://www.avma.org/ KB/Resources/Reference/AnimalWelfare/Pages/Abuse-Reporting-requirements-by-State.aspx).

Baldry, Anna C. 2005. "Animal abuse among preadolescents directly and indirectly victimized at school and at home." Criminal Behaviour and Mental Health 15(2): 97110.

Becker, Kimberly D., Jeffrey Stuewig, Veronica M. Herrera, and Laura A. McCloskey. 2004. "A study of firesetting and animal cruelty in children: Family influences and adolescent outcomes." Journal of the American Academy of Child \& Adolescent Psychiatry 43(7): 905-912.

Blair, Monique. 2017. "Police: Daughter arrested after neglecting elderly mother in deplorable home.” WKYT, March, 8. Retrieved December, 182019 (https://www. wlty.com/content/news/Daughter-arrested-after-neglecting-elderly-mother-in-deplorable-home-415741953.html).

Bright, Melissa A., Mona Sayedul Huq, Terry Spencer, Jennifer W. Applebaum, and Nancy Hardt. 2018. “Animal cruelty as an indicator of family trauma: Using adverse 
childhood experiences to look beyond child abuse and domestic violence." Child Abuse \& Neglect 76:287-296.

Collins, Elizabeth A., Anna M. Cody, Shelby Elaine McDonald, Nicole Nicotera, Frank R. Ascione, and James Herbert Williams. 2006. "A template analysis of intimate partner violence survivors' experiences of animal maltreatment: Implications for safety planning and intervention.” Violence against women 24(4):452-476.

Currie, Cheryl L. "Animal cruelty by children exposed to domestic violence." Child Abuse \& Neglect 30(4):425-435.

DeGue, Sarah, and David DiLillo. 2009. “Is animal cruelty a 'red flag' for family violence? Investigating co-occurring violence toward children, partners, and pets.” Journal of Interpersonal Violence 24(6):1036-1056.

DeGue, Sarah. 2011. "A triad of family violence: Examining overlap in the abuse of children, partners, and pets.” Pp. 245-262 in The psychology of the human-animal bond, edited by C. Blazina, G. Boyraz, \& D. S. Shen-Miller. New York, NY: Springer.

DeViney, Elizabeth, Jeffery Dickert, and Randall Lockwood. 1998. "The care of pets within child abusing families.” Pp. 305-313 in Cruelty to Animals and Interpersonal Violence, edited by R. Lockwood and F.R. Ascione. West Lafayette: Purdue University Press.

Faver, Catherine A., and Elizabeth B. Strand. 2008. "Unleashing compassion: Social work and animal abuse.” Pp. 175-199 in The International Handbook Of Animal Abuse And Cruelty: Theory, Research, And Application, edited by F. R. Ascione. West Lafayette, IN: Purdue University Press.

Febres, Jeniimarie, Hope Brasfield, Ryan C. Shorey, Joanna Elmquist, Andrew Ninnemann, Yael C. Schonbrun, Jeff R. Temple, Patricia R. Recupero, and Gregory L. Stuart. 2014. "Adulthood animal abuse among men arrested for domestic violence.” Violence Against Women 20(9):1059-1077.

Finkelhor, David, Heather Turner, Sherry L. Hamby, and Richard Ormrod. 2011. "Polyvictimization: Children's Exposure to Multiple Types of Violence, Crime, and Abuse.” National survey of children's exposure to violence. Juvenile Justice Bulletin, NCJ235504. Washington, DC: U.S. Government Printing Office.

Flynn, Clifton P. 1999. “Exploring the link between corporal punishment and children's cruelty to animals." Journal of Marriage and the Family 61(4):971-981.

Girardi, Alberta, and Joanna D. Pozzulo. 2015. "Childhood experiences with family pets and internalizing symptoms in early adulthood.” Anthrozoös 28(3):421-436.

Gullone, Eleonora and Nerida Robertson. 2008. "The relationship between bullying and animal abuse behaviors in adolescents: The importance of witnessing animal abuse." Journal of Applied Developmental Psychology 29(5): 371-379.

Haden, Sara Chiara, Shelby E. McDonald, Laura J. Booth, Frank R. Ascione, and Harold Blakelock. 2018. “An Exploratory Study of Domestic Violence: Perpetrators' Reports of Violence Against Animals.” Anthrozoös 31(3):337-352.

Hardesty, Jennifer L., Lyndal Khaw, Marcella D. Ridgway, Cheryl Weber, and Teresa Miles. 2013. "Coercive control and abused women's decisions about their pets when seeking shelter.” Journal of Interpersonal Violence 28(13):2617-2639. 
Hartman, Christie A., Tina Hageman, James Herbert Williams, and Frank R. Ascione. 2018. „Intimate partner violence and animal abuse in an immigrant-rich sample of mother-child dyads recruited from domestic violence programs." Journal of Interpersonal Violence 33(6):1030-1047.

Hodgson, Kate, and Marcia Darling. 2011. "Pets in the family: practical approaches.” Journal of the American Animal Hospital Association 47(5):299-305.

Hoffer, Tia, Holly Hargreaves-Cormany, Yvonne Muirhead, and J. Reid Meloy. 2018. “The Relationship Between Family Violence and Animal Cruelty.” Pp. 35-37 in Violence in Animal Cruelty Offenders. Springer Briefs in Psychology, Cham.

"In harm's way: Executive summary: domestic violence program responses to pets." 2010. Ohio Domestic Violence Network, Steering Committee on DV and Animal Abuse.

Irvine, Leslie. 2015. My dog always eats first: Homeless people and their animals. Boulder, CO: Lynne Rienner Publishers.

McDonald, Shelby Elaine, Anna M. Cody, Laura J. Booth, Jennifer R. Peers, Claire O’Connor Luce, James Herbert Williams, and Frank R. Ascione. 2018. "Animal Cruelty among Children in Violent Households: Children's Explanations of their Behavior.” Journal of Family Violence 33(7):469-480.

McDonald, Shelby Elaine, Elizabeth A. Collins, Anna Maternick, Nicole Nicotera, Sandra Graham-Bermann, Frank R. Ascione, and James Herbert Williams. 2019. “Intimate partner violence survivors' reports of their children's exposure to companion animal maltreatment: A qualitative study.” Journal of Interpersonal Violence 34(13):2627-2652.

McDonald, Shelby Elaine, Julia Dmitrieva, Sunny Shin, Stephanie A. Hitti, Sandra A. Graham-Bermann, Frank R. Ascione, and James Herbert Williams. 2017. “The role of callous/unemotional traits in mediating the association between animal abuse exposure and behavior problems among children exposed to intimate partner violence.” Child Abuse \& Neglect 72: 421-432.

McDonald, Shelby Elaine, Sandra A. Graham-Bermann, Anna Maternick, Frank R. Ascione, and James Herbert Williams. 2016. "Patterns of adjustment among children exposed to intimate partner violence: A person-centered approach.” Journal of Child \& Adolescent Trauma 9(2): 137-152.

McNicholas, June and G. Collis. 2006. "Animals as social supports: Insights for understanding animal-assisted therapy." Handbook on animal-assisted therapy: Theoretical foundations and guidelines for practice 2:49-72.

Musicaro, Regina Marie, Joseph Spinazzola, Joshua Arvidson, Sujata Regina Swaroop, Lisa Goldblatt Grace, Aliza Yarrow, Michael K. Suvak, and Julian D. Ford. 2019. "The complexity of adaptation to childhood polyvictimization in youth and young adults: Recommendations for multidisciplinary responders." Trauma, Violence, \& Abuse 20(1): 81-98.

National Link Coalition. 2019. How do I report suspected abuse? Retrieved September 5, 2019 (http://nationallinkcoalition.org/how-do-i-report-suspected-abuse).

Ohio Domestic Violence Network. 2019. Domestic Violence Statistics. Retrieved on December 22, 2019 (https://www.odvn.org). 
Patterson-Kane, Emily G., and Heather Piper. 2009. "Animal abuse as a sentinel for human violence: A critique.” Journal of Social Issues 65(3): 589-614.

Peak, Terry, Frank Ascione, and Jylisa Doney. 2012. "Adult protective services and animal welfare: should animal abuse and neglect be assessed during adult protective services screening?." Journal of Elder Abuse \& neglect 24(1): 37-49.

Petersen, Anne C., Joshua Joseph, Monica Feit, Committee on Law, and National Research Council. 2014. "Consequences of child abuse and neglect.” Pp. 111-174 in New Directions in Child Abuse and Neglect Research. National Academies Press, US.

Randour, Michael L. 2018. “Animal cruelty crimes added to NIBRS.” Sheriff \& Deputy 70(4):36.

Risley-Curtiss, Christina. 2010. "Social work practitioners and the human-companion animal bond: A national study.” Social Work 55(1) 38-46.

Roguski, Michael. 2012. "Pets as pawns: The co-existence of animal cruelty and family violence.” Auckland: Royal New Zealand Society for the Prevention of Cruelty to Animals. Retrieved on December 22, 2019 (http://www.communityresearch.org. nz/wp-content/uploads/formidable/Pets-as-Pawns-Research-Report-Final.pdf).

Schambon v. Commonwealth, 821 S.W.2d 804 (1991)

Simmons, Catherine A. and Peter Lehmann. 2007. "Exploring the link between pet abuse and controlling behaviors in violent relationships.” Journal of interpersonal violence 22(9): 1211-1222.

The State v. Boarman, 459 S.E.2d 395 (1995).

Turner, Wendy G. 2006. "The role of companion animals throughout the family life cycle.” Journal of Family Social Work 9(4):11-21

Walton-Moss, Benita J., Jennifer Manganello, Victoria Frye, and Jacquelyn C. Campbell. 2005. "Risk factors for intimate partner violence and associated injury among urban women." Journal of Community Health 30(5):377-389.

Wood, Lisa, Karen Martin, Hayley Christian, Andrea Nathan, Claire Lauritsen, Steve Houghton, Ichiro Kawachi, and Sandra McCune. 2015. “The pet factor-companion animals as a conduit for getting to know people, friendship formation and social support.” PloS one 10(4): e0122085.

\section{BIOGRAPHICAL NOTE}

Aviva Vincent is an adjunct faculty in social work at the Mandel School of Applied Social Sciences at Case Western Reserve University, an instructor of Animal-Assisted Interventions in the Veterinary Social Work Certificate Program at the University of Tennessee, and the Director of Program Quality at Fieldstone Farm Therapeutic Riding Centre in Chagrin Falls, Ohio, USA.

Shelby McDonald is an Assistant Professor in social work and core faculty in the Clark-Hill Institute for Positive Youth Development in the Department of Psychology at Virginia Commonwealth University in Virginia, USA.

Bethanie Poe is the Middle Tennessee Human-Animal Bond in Tennessee (HABIT) Coordinator at the University of Tennessee, in Knoxville Tennessee, USA.

Vicki Deisner is the Government Affairs Representative in Ohio for the Animal Welfare Institute, USA. 
OPEN ACCESS: This article is distributed under the terms of the Creative Commons Attribution Non-commercial License (CC BY-NC 4.0) which permits any non-commercial use, and reproduction in any medium, provided the original author(s) and source are credited.

ARTICLE HISTORY: Received 2019-08-30 / Accepted 2019-11-24 
